\title{
Tracking errors and their determinants: Evidence from Hong Kong exchange traded funds
}

Patrick Kuok-Kun Chu, ${ }^{1}$

Faculty of Business Administration, University of Macau, Macao.

\begin{abstract}
This paper uses panel data to find the determinants of tracking errors in exchange traded funds (ETFs) in the Hong Kong stock market. A comparison of tracking errors between physical and synthetic ETFs also indicates that the synthetic ETFs have higher tracking errors. The magnitude of tracking errors is found to be negatively related to size but positively related to dividend yield, trading volumes of funds, and market risk. However, this study also finds that expense ratio has a negative impact on tracking error, which is not consistent with previous studies, and which this paper addresses.
\end{abstract}

JEL Codes: G15, G20, G23

Keywords: Exchange traded funds, ETFs, tracking error, panel regression model, fixed effects estimation.

\section{Introduction}

The first exchange traded fund (hereafter ETF) appeared in Canada in 1989, with the creation of the Toronto Index Participation Fund (TIP 35). The first ETF in the United States was Standard \& Poor's 500 Depository Receipts (SPDRs), which was designed to passively mimic the S\&P 500 index. Asia followed suit in 1999, when its first ETF, the Hong Kong Tracker Fund, was launched on 12 Nov 1999. ETFs are passively managed funds that aim to closely track the performance of indices. They are legally defined as

\footnotetext{
${ }^{1}$ Corresponding author, email: patrickc@umac.mo, phone: +853 8822-4166, address: Rm. 3056, FBA, University of Macau, E22, Avenida da Universidade, Taipa, Macao.
} 
open-end companies or unit investment trusts, but is different from those in the ways that they are traded. ETFs issue their shares in large blocks, known as creation units, in the stock market, and investors can buy and sell individual shares, as in trading stocks. ETFs combine the benefits of diversifying investment through index investing and the flexibility of trading at any time during a market's trading hours. ETFs have become increasingly popular, because they represent portfolios of securities designed to track the performance of indices, offering an efficient way for investors to obtain cost-effective exposure. Moreover, ETFs have significantly lower transaction costs than actively managed mutual funds, because there is no subscription fee for ETFs. In Hong Kong, ETFs that track indices that do not comprise any Hong Kong stocks are even exempt from stamp duties. Other features that make ETFs attractive are their high degree of transparency in identifying the constituents underlying funds, their intraday valuation, their ability to be traded by brokers like stocks, and their liquidity, which is enhanced by market makers. ETFs are also eligible for short selling, which provides investment opportunities when investors foresee a bear market in the near future. Portfolio managers can use ETFs as investment tools to help execute dynamic trading strategies and individual investors can use them to participate in foreign stock markets and as tools to diversify their investments. Miffre (2006) has empirically demonstrated that country-specific ETFs can enhance global asset allocation strategies at a low cost, with a low level of tracking error, and in a tax-efficient manner. The ETF industry in the U.S. has experienced rapid growth over the last decade, with a 5-year average annual growth rate of $33 \%$ (Schuster, 2008).

However, ETFs still involve some disadvantages. For example, they incur some of the same transaction costs as stocks, such as bid/ask spreads and brokerage costs, and investors can trade ETFs at a premium or discount to the net asset value (NAV). 
ETFs are currently playing an increasingly important role in Hong Kong. The number of ETFs has increased from 18 in 2008 to 76 in 2011. However, compared with financial markets in western countries, the Hong Kong ETF segment is still in its emerging stages. There are over 1,114 ETFs listed in the U.S., which manage assets worth over 1,055 billion dollars. However, as of the end of 2011, there are only 76 listed ETFs available to investors in Hong Kong. Among these 76 ETFs, 22 are physical ETFs, which directly buy all of the assets needed to replicate the composition and weighting of their benchmarks or buy a portion of the assets needed to replicate the composition along with other assets that have a high degree of correlation with the underlying benchmark. The remaining 54 are synthetic ETFs, which typically invest in financial derivative instruments to replicate their benchmarks' performance. Synthetic ETFs can be identified by the letter $X$ at the beginning of their stock names. In terms of the markets that they trace, 44 trace Greater China markets, 26 trace other markets, and the remaining 6 mimic the returns of bonds, commodities, or money markets. The significant increase in number and turnovers of ETFs in these five years, a need of research in the ETF market in Hong Kong is necessary since there are few.

The objective of an ETF is different from that of an actively managed fund, in that ETFs aim to replicate the return and risk of the underlying benchmark index. Despite their stated purpose of tracking underlying benchmarks, not all ETFs track these benchmarks with an equal level of accuracy. If an index fund is not able to replicate the return on a benchmark index perfectly, it is regarded as unable to meet its investment objectives. Roll (1992) suggests that the level of tracking error may be an important criterion for assessing an index fund's performance, because funds' differential returns may indicate whether their managers' investment processes have been successfully implemented, even in the case of non-indexed equity funds. Pope and Yadav (1994) also 
agree that tracking errors are crucial to structuring and managing index funds. The performance of an ETF is not guaranteed to be identical to its underlying tracking index, because an index only represents a calculation derived from a portfolio of stocks, and is not subject to the same market frictions as an ETF.

The purpose of this study is twofold. Its first objective is to explore the possible tracking errors of ETFs traded in Hong Kong, and to compare the tracking errors of two classes of ETFs, physical and synthetic, which may provide further evidence of whether Hong Kong ETFs are traded at their fundamental values. The second objective is to identify rational factors that explain the observed tracking errors. A multifactor panel regression model is constructed to explain tracking errors, based on a set of operating factors. Using panel regression models to find out the determinants of tracking errors is unique in this study and this study is first in academics.

This study may provide some insight into Hong Kong ETFs, for both fund managers and ETF investors. Fund managers who include some ETFs listed in the Hong Kong Stock Exchanges (HKEX) in their portfolios should be aware of the determinants of tracking errors that may influence their fund portfolios' performances. This study highlights the challenges facing fund managers who seek to trace markets at a relatively lower cost by investing in ETFs rather than physically holding stocks. Beside this, it provides ETF investors with knowledge of the most significant factors in tracking errors, and points out that the greater tracking errors involved in synthetic ETFs may be one of the reasons why they are not popular in the Hong Kong market.

The rest of the paper is organized as follows. Section 2 provides a brief literature review of studies on the performance of ETFs. Section 3 describes the data involved in this study, and Section 4 explains the research methodology employed. Section 5 discusses the study's findings, while Section 6 offers a conclusion. 


\section{Literature Review}

There are two classes of index-linked products in the market: open-ended managed passive index funds and ETFs traded on the stock market. The implementation of index management in passive index funds is not particularly easy. Practical implementation may involve frictions with regard to trading expenses, issues with the reinvestment of dividends, and delays in reallocating portfolios when constituent stocks in tracking indices changes. These frictions may cause differences in returns between funds and indices. A study by Frino and Gallagher (2001) is the first to use tracking error as a measure of the performance of S\&P 500 index funds. It finds that a sample of funds underperformed the market by $0.29 \%$ per annum on an after-cost basis, and that their mean tracking error was significantly higher in the months of January and May than in other months and at its lowest in June. They hypothesize that delays in receiving dividends and changes in the S\&P 500 index may be factors explaining tracking errors. They also suggest that tracking errors are directly related to expenses, with lower expense ratios resulting in lower tracking errors.

Frino and Gallagher (2002) extend their previous research to a sample of Australian index funds. They find a substantially high percentage of tracking error, ranging from $0.074 \%$ to $0.224 \%$ per month. A regression model of tracking error involving the hypothesized determinants confirms that tracking error is positively and significantly related to fund cash flows, the cost of trading stocks in an index portfolio, and the volatility of a benchmark. It also shows that tracking error is positively but insignificantly related to dividend yields of stocks comprising an index and the market capitalization percentage of stocks included and excluded from the index. 
Cresson, Cudd, and Lipscomb (2002) examine the tracking performance of a set of daily returns of S\&P 500 index funds by applying a naive measure of tracking performance (fund R-square) to the set. They find that the tracking performance measures based on daily returns are substantially fewer than those found in previous research based on monthly returns. A regression of transformed R-squares for each index fund on the determinants indicates that the R-square values are positively related to fund size and fund manager tenure.

Existing studies on the prices and performances of active mutual funds and open-end index mutual funds are extensive, but studies on the performance of ETFs are limited in number, due to the limited data available as a result of their short period of existence. Some studies have compared conventional index funds with ETFs. Dellva (2001) finds that ETFs have higher transaction costs associated with trading, and argues that the few or non-existent benefits of tax deferral may be one of the reasons why few long-term retirement-class investors utilize these products. Kostovetsky (2003) finds that the cost differences between index mutual funds and ETFs are due to management fees, shareholder transaction fees, tax efficiency, and other qualitative differences. Guedj and Huang (2008) examine the liquidity differences between ETFs and conventional index funds, and conclude that investors with similar liquidity needs should be indifferent with regard to differentiating between the two investment instruments. They also find that while the overall transaction costs for all investors are the same in ETFs and conventional index funds, the allocation of costs is different. Agapova (2011) examines the substitutability of these two similar investment vehicles by comparing aggregate fund flows into conventional index funds to those into ETFs for various underlying indexes, and finds that the two vehicles can be regarded as substitutes for one another, but not perfect ones. Their coexistence can be explained by a clientele effect, in that ETFs do not 
replace index funds but add to the completeness of the market.

Elton, Gruber, Comer, and Li (2002) find that the net asset value of the first ETF in the U.S., SPDR, can be kept close to the market price. However, they find that SPDR underperforms the S\&P index, primarily due to the loss of income caused by holding dividends received on underlying shares in cash. Ivanov (2011) finds that the volatility of SPDR near the NYSE close is quite similar to the volatility of the S\&P 500 index's future contract, which is also documented by Chang, Jain, and Locke (1995), and find that SPDR exhibits a U-shaped pattern. However, this volatility was also found to consistently drop in the 15 minutes after the NYSE close. One of the possible reasons for this is that the SPDR NAV should not change when the component stocks of the underlying indexes stop trading, as the trading price is only determined by supply and demand and thus should remain close to NAV, because participants' arbitrage activities in the 16:00-16:15 period are virtually non-existent.

Pennathur, Delcoure, and Anderson (2002) evaluate the diversification ability of iShares and closed-end country funds, using a single-index model and a two-factor model. The single-index model indicates that iShares replicate the home index, demonstrating their diversification ability. However, the two-factor model demonstrates that both iShares and closed-end country funds maintain considerable exposure to the U.S. stock market, and that there is apparently no diversification substitute for direct foreign investment.

Jares and Lavin (2004) examine the pricing efficiency of foreign ETFs and find that the asynchronous nature of trading and the information flow across different markets may be the cause of premiums and discounts in ETF valuation. The study documents that U.S. information sources have causal relationships with the daily returns of Japanese and Hong Kong iShares. 
Regarding the tracking performance of ETFs, some studies have not only evaluated the size of tracking errors, but also investigated what factors explain ETF tracking errors and ETF premiums and discounts. Delcoure and Zhong (2007) find that the premiums of iShares, as newly developed exchange-traded world equity index funds, are $10 \%$ to $15 \%$, even after controlling for transaction costs and time-zone measurement errors, but that the deviations of iShares' prices from their NAVs are not persistent and converge to zero over the short term. They also find that exchange rate volatility, political and financial crises, institutional ownership, bid-ask spread, trading volume, and conditional correlations between U.S. and home markets are significant factors affecting iShares' premiums.

Tse and Martinez (2007) analyze the price volatility of international iShares, using U.S. Eastern Time as a reference point. They find that the Asian and European ETFs have higher daytime volatility than overnight volatility, which indicates that prices are mainly driven by information released during each local market's trading session.

Madura and Ngo (2008) find that the characteristics that have been determined to be effective indicators of individual stock price performance, including size, trading volume, and momentum, are also effective indicators of ETF price performance, but that these indicators become ineffective when each type of ETF is isolated.

Aber, Li, and Can (2009) explore the tracking errors of iShares by using conventional measures, and find that there is a slight inability to track their underlying benchmarks. A separate study indicates that Vanguard conventional index funds can be more easily tracked than their corresponding iShares competitors.

Rompotis (2009) also finds that the returns of ETFs and index funds are slightly inferior to the returns of benchmarks. The author finds a positive relationship between tracking error and expense ratios, which contrasts with the commonly held belief that 
expenses usually erode performance.

Johnson (2009) finds that variables such as the positive returns of foreign indices relative to US indices and whether foreign exchanges trade simultaneously with US markets are significant explanatory variables of the existence of tracking errors between foreign ETFs and underlying home indices, on a daily and monthly return basis.

Shin and Soydemir (2010) estimated the tracking errors of 26 ETFs by using three different methods. They found that the tracking errors were significantly different from zero, and their persistence was displayed by the results of a serial correlation test and run test. A larger persistence level was found among Asian ETFs, which reveals that Asian markets are less efficient in disseminating information. Shin and Soydemir (2010) also searched for determinants of tracking errors. Among a number of underlying factors, such as expense ratio, dividends, exchange rate, and spreads of trading prices, only changes in exchange rates were found to be a significant source of tracking errors. The Jensen's alpha in this study indicated that risk-adjusted returns were significantly inferior to benchmark returns for all studied ETFs, which reveals that passive investment strategies may not outperform market returns.

Blitz, Huij, and Swinkels (2012) find that not only fund expenses but also dividend withholding taxes may explain the performance differences between funds that track different benchmarks and time variations in fund performance.

\section{Data}

This study analyzes the tracking errors of 21 ETFs listed on the Hong Kong Stock Exchanges, for which daily prices are available for any complete year over the period from 2009 to 2011. The daily prices, dividend yields, and trading volumes of the ETFs, 
from their date of inception to December 312011 were obtained from DATASTREAM of Thomson Financial Limited, and were checked against the returns supplied directly by investment managers. Financial data including fund sizes and expenses over the period 2009-2011 were taken from the annual financial statements published by fund managers and listing agents. The daily closing quotes of each benchmark index were also acquired from DATASTREAM.

Table 1 presents the profile of the sample ETFs, including name of fund, benchmark index being traced, date of inception, fund size as of 31 December 2011, and expense ratio. The study is free of survivorship bias.

[Insert Table 1 Here]

\section{Research Methodology and Data}

\subsection{Determining the magnitude of tracking errors}

Roll (1992) suggests that level of tracking error may be an important criterion for assessing ETF performance. Pope and Yadav (1994) agree, and argue that tracking errors are crucial in structuring and managing ETFs. Tracking error represents the difference between the performance of an ETF and that of its target index. Pope and Yadav (1994) suggest three different definitions of tracking error.

The first definition of tracking error is the absolute difference in returns between the fund and the index, $T E_{1}$. This definition provides a measure of the extent to which the returns on an ETF $i\left(R_{i, t}\right)$ differ from the returns on the underlying benchmark index 
$b\left(R_{b, t}\right)$ over the sample period, and treats any absolute deviation in returns as tracking error. This definition of tracking error is calculated as follows:

$$
T E_{1}=\frac{\sum_{t=1}^{n}\left|e_{i, t}\right|}{n}
$$

where $e_{i, t}=R_{i, t}-R_{b, t} ; R_{i, t}=$ the logarithmic return of the ETF $i$ in period $t, R_{b, t}=$ the return of the benchmark index $b$ in period $t$, and $n=$ the number of periods

The second way to measure tracking error $\left(T E_{2}\right)$ is to compute the standard deviation of the differences between returns on ETF and the benchmark indices, which is calculated as follows:

$$
T E_{2}=\sqrt{\frac{1}{n-1} \sum_{t=1}^{n}\left(e_{i, t}-\bar{e}_{i}\right)^{2}}
$$

Using standard deviation to measure the tracking error requires the assumption of serially uncorrelated return differences, $e_{i, t}$. This definition may not be appropriate for daily data because daily returns can almost certainly be serially correlated. The other shortcoming of this definition is that if a fund consistently underperforms or outperforms the target index by same magnitude, the tracking error measured by the standard deviation may lead to a result of zero. 
The third way to estimate tracking error $\left(T E_{3}\right)$ is to find the standard error of regression $(S E R)$ in a CAPM model estimate of the daily ETF return on benchmark index return. The CAPM model is as follow:

$$
R_{i, t}=\alpha+\beta \cdot R_{b, t}+\varepsilon_{t}
$$

where $R_{i, t}=$ the logarithmic return of the ETF $i$ in period $t, R_{b, t}=$ the return of the benchmark index $b$ in period $t, \alpha$ and $\beta$ are the regression coefficients.

However, Pope and Yadav (1994) point out two problems underlying the use of this measure. First, if the beta is not exactly equal to one, this measure may result in a value different from $T E_{S D, i}$ and secondly, this approach may overestimate the tracking error if the relationship in the Jensen model is not linear.

Cresson, Cudd, and Lipscomb (2002) add a fourth method of estimating tracking error $\left(T E_{4}\right)$ to the above three, by using the value of the R-square of the CAPM model defined in equation (3). The authors suggest that using the R-square as the measure of tracking error also indicates the degree to which the ETF mimics the respective benchmark index, and that it is therefore a more straightforward measure.

The magnitude of tracking error may indicate: 1. how closely the ETF is tracking its target index and 2. the size of the cost that routinely erodes the ETF returns.

\subsection{Determinants associated with tracking errors}

To determine whether tracking errors are associated with the selected operating characteristics, the tracking errors of ETFs were regressed for selected ETF operating 
characteristics. The adoption of different portfolio strategies may affect the replication performance of ETFs. Each of the factors that may affect tracking errors is discussed below.

The size of ETFs, as measured by amounts of total assets, is hypothesized to be the first factor in tracking errors. Size is expected to be negatively related to tracking error, because larger ETFs may face lower transaction costs, due to economies of scale. However, the opposite has been documented for actively managed funds. Grinblatt and Titman (1989) find that fund size is inversely related to both hypothesized and actual returns, which contradicts our expectations.

The next factor included in this analysis is expense scaled by ETF size. Frino and Gallagher (2002) document that tracking errors are positively related to expenses, which indicates that lower expense ratios result in lower tracking errors. Expenses are the explicit costs of trading activities in stock markets, including brokerage fees and stamp duties, which can influence an ETF's ability to replicate index performance. Indices are computed based on an assumption of costless transactions, but in reality, funds are required to trade in financial markets, and explicit transaction costs are incurred. These explicit transaction costs can erode ETF returns and lead to tracking errors.

Dividend yield may also lead to tracking errors. When the listed stocks that an index is comprised of pay dividends, the index immediately assumes that the dividends are re-invested in the stocks on the ex-dividend day. However, in reality, investors face delays in receiving dividends in cash. Fund managers have to wait to receive dividends before they are able to reinvest, and their reinvestment activities also incur transaction costs that are not considered in the computation of market indices. These delays in receiving dividends and costs incurred in re-investment may erode ETFs' abilities to replicate index performance. There is a possible positive relationship between the level of 
dividends paid by the constituent stocks in an index and an ETF's tracking error.

The liquidity of ETFs is hypothesized to be related to the magnitudes of tracking errors. Higher liquidity leads to greater cash inflows to ETFs. This may reduce a fund's trading costs and its level of tracking error. The respective levels of risk in the financial markets that an ETF is tracing may also be a factor. Higher risk in the market may make it more difficult for an ETF to replicate performance, and thus could lead to a higher level of tracking error.

Given the above, the variables in this study regarding the operating characteristics of ETFs include the natural logarithm of ETF size (SIZE), whose original value is in million $\mathrm{HKD}$, the expense ratio $(E X P)$, which is defined as the expense of funds scaled to the ETF's size, dividend yields (DIV), as measured by the ratio of average dividends and average trading prices of the ETF, ETF liquidity, as measured by the natural logarithm of the average daily trading volume $(V O L)$, and market risk (RISK), as measured by the average standard deviation of daily returns.

The dataset is a panel with 21 cross-sections (ETFs) and three time periods (2009-2011). The use of the panel data model, rather than cross-sectional or time series models, was chosen because panel data can account for individual differences or heterogeneity. Furthermore, a panel dataset can involve data from a time period that is long enough to allow dynamic factors to be studied. Since the number of cross-sections in this study is fairly large, the techniques of using seemingly unrelated regressions (SUR) or the panel regression model, including the same number of dummy variables as the number of cross-sections in the intercept, are not quite appropriate. A model with fixed effects estimators may be adapted to panel data with a large number of cross-sections. The fixed effects estimation in this study is as follows: 


$$
\widetilde{y}_{i t}=\beta_{1} \widetilde{x}_{1 i t}+\beta_{2} \widetilde{x}_{2 i t}+\cdots+\widetilde{\varepsilon}_{i t}
$$

where the "tilde" notation $\tilde{y}_{i t}=y_{i t}-\bar{y}_{i}$ indicates that the variables are in deviation from the mean. A complete panel regression model with fixed effects estimation will then be:

$$
T \widetilde{E}_{i, t}=\beta_{1} \cdot S I \widetilde{Z} E_{i, t}+\beta_{2} \cdot E \widetilde{X} P_{i, t}+\beta_{3} \cdot D \widetilde{I} V_{i, t}+\beta_{4} \cdot V \widetilde{O} L_{i, t}+\beta_{5} \cdot R I \widetilde{S} K_{i, t}+\widetilde{\varepsilon}_{i, t}
$$

where $S I Z E_{i t}$ is the natural logarithm of ETF size, EXP $P_{i t}$ is the expense ratio defined as the expense of funds scaled to the ETF's size, $D I V_{i t}$ is the dividend yields measured by the ratio of average dividends and average trading prices of the ETF, $V O L_{i t}$ is ETF liquidity measured by the natural logarithm of the average daily trading volume, and $R I S K_{i t}$ is the market risk. The "tilde" notation indicates $T \widetilde{E}_{i t}=T E_{i t}-\overline{T E}_{i}$, $S I \widetilde{Z} E_{i t}=S I Z E_{i t}-\overline{S I Z E}_{i} \quad, \quad E \widetilde{X} P_{i t}=E X P_{i t}-\overline{E X P}_{i} \quad, \quad D \widetilde{I} V_{i t}=D I V_{i t}-\overline{D I V}_{i}$ $V \widetilde{O} L_{i t}=V O L_{i t}-\overline{V O L}_{i}$, and $R I \widetilde{S} K_{i t}=R I S K_{i t}-\overline{R I S K}_{i}$

To overcome the problem of multicollinearity among the regressors, we first analyze the tracking errors with respect to the ETFs' natural logarithmic sizes (SIZE), scaled expense ratios $(E X P)$, and dividend yields $(D I V)$. The following model with fixed effects estimation is then obtained:

$$
T \widetilde{E}_{i, t}=\beta_{1} \cdot S I \widetilde{Z} E_{i, t}+\beta_{2} \cdot E \widetilde{X} P_{i, t}+\beta_{3} \cdot D \widetilde{I} V_{i, t}+\widetilde{\mathcal{E}}_{i, t}
$$

The trading volume and market risk are then considered in the second step, and the second panel regression model with fixed effects estimation yields: 


$$
T \widetilde{E}_{i, t}=\beta_{1} \cdot V \widetilde{O} L_{i, t}+\beta_{2} \cdot R I \widetilde{S} K_{i, t}+\widetilde{\varepsilon}_{i, t}
$$

\section{Results}

\subsection{Tracking errors of ETFS}

The tracking errors of all of the ETFs included in this study, for the entire sample period available, are reported in table 2 . Based on the first definition of tracking error $\left(T E_{1}\right)$, the daily tracking error averages range from $0.2495 \%$ to $2.1311 \%$ across ETFs, the tracking errors based on the standard deviation of the return differences $\left(T E_{2}\right)$ range from $0.3638 \%$ to $3.0763 \%$, and the daily tracking errors of each ETF computed by finding the standard error of regression of the CAPM model defined in equation (3) $\left(T E_{3}\right)$ range between $0.3602 \%$ and $2.7365 \%$. These results indicate that the Hong Kong ETFs fall well short of perfectly tracking the underlying indices, and seem to have difficulty achieving index returns. From the viewpoint of investors, the ETFs do not provide fully efficient tracking of the underlying indices. The daily tracking errors of Hong Kong ETFs documented in this study are also comparatively higher than those documented in the U.S. $(0.039 \%$ to $0.110 \%$ per month) and in Australia $(0.074 \%$ to $0.224 \%$ per month). The tracking errors based on the first three definitions documented in this study are based on daily figures, which differ from those reported in previous studies that have primarily used monthly data (Frino and Gallagher, 2001; 2002). The tracking errors reflect the inherent frictions that ETF managers face, such as administrative expenses, transaction costs, commissions, underinvested dividends, and delays in ETFs' adjustments of portfolios to match changes in constituent stocks in indices. 
The tracking errors of all ETFs, based on the magnitude of the R-square of the CAPM model $\left(T E_{4}\right)$ are also reported in table 2. The R-square for the entire sample ranges from a low of 0.0005 to a high of 0.9649 . The values of the R-square reported in this study differ from those documented in studies by Frino and Gallagher $(2001,2002)$, in which the values of the R-square range from 0.997 to 1.000 in the U.S. and from 0.993 to 1.000 in Australian cases. However, both of these previous studies were based on monthly returns. These results once again demonstrate the difference in measuring the tracking errors of ETFs using daily versus monthly return figures. A fairer comparison is with the daily tracking errors employing the R-square of S\&P 500 index funds documented in Cresson, Cudd, and Lipscomb (2002), which found values ranging from 0.9052 to 0.9609 . However, the values of the R-square documented in this study are still substantially below those documented in the U.S. and Australia. The substantially higher tracking errors in Hong Kong ETFs may reflect the higher cost of trading the underlying portfolios of stocks in Hong Kong or the higher cost of trading overseas stocks for Hong Kong ETF managers.

\section{[Insert Table 2 Here]}

The author's previous study (Chu, 2011) suggests that one of the reasons for higher tracking errors in Hong Kong ETFs is that some are synthetic ETFs. To test this possibility, a pooled-variance t-test on the claim that the synthetic ETFs have significantly higher tracking errors than physical ETFs was performed, and the results are presented in panel A of table 3. The test statistics support the claim at a 5\% level of significance. The reason why synthetic ETFs have higher tracking errors is easy to understand. Synthetic ETFs may not find derivatives that exactly match the stocks being 
included in their benchmark indices, meaning that their performance may not trace the performance of their benchmark indices perfectly.

Panel B of table 3 presents a pool-variance t-test of the difference between the mean alpha and beta values of physical and synthetic ETFs. The test results do not indicate any difference between these means. Moreover, the mean alpha of synthetic ETFs is a larger negative number, which could be explained by the inferior performance of synthetic ETF managers in using swaps or derivatives to replicate the performance of benchmarks. The mean beta values between physical and synthetic ETFs are not significantly different, as indicated by the t-test, but the mean beta values of all sample ETFs differ significantly from unity (t-statistics $=-3.73$, p-value $=0.0013)$, which verifies the tracking error results.

[Insert Table 3 Here]

Finally, the similarity of the tracking errors found by applying different definitions is investigated by performing a paired-sample t-test on the mean differences in tracking errors by different definitions. Table 4 summarizes the results. The test statistics indicate that the tracking errors calculated by the first method $\left(T E_{1}\right)$ and the second method $\left(T E_{2}\right)$ are significantly different, at the $1 \%$ significance level. This finding is repeated when we test the mean difference of tracking errors computed by $T E_{1}, T E_{3}$, $T E_{2}$, and $T E_{3}$. We can thus conclude that these methods arrive at different estimations of tracking errors, and that it is quite important to select an appropriate method for calculating tracking errors.

[Insert Table 4 Here] 


\subsection{Determinants of tracking errors}

Table 5 presents the results of the panel regression model with fixed effects estimation for 21 ETFs over the period 2009-2011. Tracking errors computed by methods $T E_{1}$ to $T E_{3}$ are used as dependent variables.

Model number (6) includes the determinants of ETFs' logarithmic size, scaled expense ratio, and dividend yields. Model number (7) includes the determinants of logarithmic trading volume and market risk. The results indicate that the tracking errors are generally influenced by the size, expense ratio, and market risk at either the 0.05 or 0.01 significance level. Tracking error $T E_{3}$ is not affected by dividend yield, but has a positive association with $T E_{1}$ and $T E_{2}$. The trading volume is not significant to explain the tracking errors, and the sign of the coefficient is different when different measures of tracking error are used.

As is consistent with expectations, table 5 points out that the coefficients of size are negative regardless of which measure of tracking errors is used, indicating that larger funds produce smaller tracking errors. This confirms our expectation that larger funds should have lower transaction costs in trading stocks, due to the economies of scale involved, and this produces lower tracking errors for larger index funds. The signs of the coefficients of the other two operating characteristics, dividend yields and market risk, are also in accordance with our expectations. Dividend yield is found to have a positive impact on tracking error, which supports the theory that delays in receiving dividends and costs incurred in re-investment may erode ETFs' abilities to replicate index performance. The positive sign of the coefficients of market risk shows that higher risk in the market may make it more difficult for ETFs to replicate performance, leading to greater tracking 
errors.

[Insert Table 5 Here]

The results show that the scaled expense ratios of the funds $(E X P)$ have negative impacts on tracking errors, which is contrary to results documented in existing literature. Most previous studies find that index funds with higher expense ratios should have a lower ability to capture the performance of benchmark indices. The reason why our results are not consistent with these studies is that our sample consists of both physical and synthetic ETFs. Table 3 has suggested that synthetic ETFs have larger tacking errors. The lower expense ratios of synthetic ETFs may be explained by the construction of portfolios of swaps or derivatives that do not completely replicate the performances of benchmarks. The commissions and transaction costs incurred are also lower than those of physical ETFs, which have to hold a portfolio of stocks identical to the benchmark index. Incomplete portfolios of swaps or derivatives may also explain why synthetic ETFs have lower abilities to trace the market, and thus have higher tracking errors. Tables 6 and 7 report the results of models (6) and (7) performed on physical ETFs and synthetic ETFs separately. Table 6 indicates the regression coefficient of EXP is insignificant negative for physical ETFs; while table 7 indicates that of EXP becomes significant negative for synthetic ETFs. These separate analyses support our suspect that some synthetic ETFs have incomplete portfolios such that they do not have so high trading expenses but they have higher inability to trace the market.

[Insert Table 6 Here]

[Insert Table 7 Here] 


\section{Conclusion}

Exchange traded funds (ETFs) have grown in popularity since their first introduction to Hong Kong in 1999. This study extends the author's previous study (Chu, 2010) to compare the tracking errors of two groups of ETFs, physical and synthetic ETFs, traded in Hong Kong. In doing so, it is the first study using panel regression models to find out the determinants of tracking errors. This study finds that the magnitude of tracking errors of Hong Kong ETFs using daily figures are comparatively higher than those in the U.S. and Australia. This implies that fund managers have difficulties in replicating the performance of the underlying indices by using synthetic tools rather than investing in the respective constituent stocks directly, and that ETF investors may face additional risks as a result. The study's other implication is that the magnitudes of tracking errors increase when daily data are employed. The study also finds that the tracking errors of synthetic ETFs are significantly higher than those of physical ETFs. The magnitude of tracking errors is found to be negatively related to size and expense ratio, but positively related to dividend yield, trading volume, and market risk. This conforms to results found in other studies, which indicate that large ETFs should have lower trading costs and thus lower tracking errors, due to economies of scale, that delays in receiving dividends and the costs incurred increase tracking errors, and that higher risks in a market may make it more difficult for ETF managers to replicate benchmark performances. Synthetic ETFs are found to have lower expense ratios than physical ETFs, which indicates that synthetic fund managers do not use complete portfolios of swaps or derivatives that perfectly replicate the market, and thus that the transaction costs involved are lower than those involved in physical funds. This explains why we find a negative 
impact of expense ratio on tracking errors, which is not consistent with the findings of existing studies. The results reported here may raise arguments on whether exchange traded funds are good alternatives to active managed funds and retailed passively managed funds, and may suggest that it is not sensible for investors to rush into investing in ETFs, despite the fact that the popularity of these investment vehicles has been increasing for several years.

\section{Acknowledgement}

The author thanks the editor, an anonymous referee, colleagues of University of Macau for helpful comments, and graduates of University of Macau Ms. Bella Beibei Zhang and Ms. Juicy Bing Bai for their helps in handling and collecting data.

This research is funded by multi-year research grant of University of Macau.

\section{Bibliography}

Aber, J. W., Li, D. and Can, L. (2009) Price Volatility and Tracking Ability of ETFs, Journal of Asset Management, 10, 210-221.

Agapova, A. (2011) Conventional Mutual Index Funds Versus Exchange-Traded Funds, Journal of Financial Markets, 14, 323-343.

Blitz, D., Huij, J. and Swinkels, L. (2012) The Performance of European Index Funds and Exchange-Traded Funds, European Financial Management, 18, 649-662. 
Chang, E. C., Jain, P. C. and Locke, P. R. (1995) Standard \& Poor's 500 Index Futures Volatility and Price Changes around the New York Stock Exchange Close, Journal of Business, 68, 61-84.

Chu, P. K. K. (2011) Study on the Tracking Errors and their Determinants: Evidence from Hong Kong Exchange Traded Funds (ETFs), Applied Financial Economics, 21, 309-315.

Cresson, J., Cudd, R. and Lipscomb, T. (2002) The Early Attraction of S\&P Index Funds: Is Perfect Tracking Performance an Illusion? Managerial Finance, 28, 1-8.

Delcoure, N., and Zhong, M. (2007) On the Premiums of iShares, Journal of Empirical Finance, 14, 168-195.

Dellva, W. (2001) Exchange-Traded Funds Not for Everyone, Journal of Financial Planning, 14, 110-124.

Elton, E. J., Gruber, M. J., Comer, G., and Li, K. (2002) Spiders: Where are the Bugs? Journal of Business, 75, 453-472.

Frino, A. and Gallagher, D. (2001) Tracking S\&P500 Index Funds, Journal of Portfolio Management, 28, 44-55.

Frino, A. and Gallagher, D. (2002) Is Index Performance Achievable? An Analysis of Australian Equity Index Funds, ABACUS, 38, 200-214. 
Grinblatt, M. and Titman, S. (1989) Mutual Fund Performance: An Analysis of Quarterly Portfolio Holdings, Journal of Business, 62, 393-416.

Guedj, I. and Huang, J. C. (2008) Are ETFs Replacing Index Mutual Funds? SSRN Working Paper.

Ivanov, S. (2011) ETF Volatility around the New York Stock Exchange Close, Journal of Accounting and Finance, 11(4), 37-46.

Jares, T. and Lavin, A. (2004) Japan and Hong Kong Exchange Traded Funds (ETFs): Discounts, Returns, and Trading Strategies, Journal of Financial Services Research, 25, 96-104.

Johnson, W. (2009) Tracking Errors of Exchange Traded Funds, Journal of Asset Management, 10, 253-262.

Kostovetsky, L. (2003) Index Mutual Funds and Exchange-Traded Funds, Journal of Portfolio Management, 29, 80-92.

Madura, J., \& Ngo, T. (2008) Clustered Synergies in the Takeover Market, Journal of Financial Research, 31, 333-356.

Miffre, J. (2006) Country-specific ETFs: An Efficient Approach to Global Asset Allocation. EDHEC Business School Working Paper. 
Pennathur, A. K., Delcoure, N., Anderson, D. (2002) Diversification Benefits of iShares and Closed-end Country Funds, Journal of Financial Research, 25, 541-557.

Pope, P. and Yadav, P. (1994) Discovering Errors in Tracking Error, Journal of Portfolio Management, 20, 27-32.

Roll, R. (1992) A Mean/Variance Analysis of Tracking Error, Journal of Portfolio Management, 18, 13-22.

Rompotis, G. (2009) Interfamily Competition on Index Tracking: The Case of the Vanguard ETFs and Index Funds, Journal of Asset Management, 10, 263-278.

Schuster A. J. (2008). ETFs: The next 10 years. Global Exchanges and ETFs report, 34-35.

Shin, S. and Soydemir, G. (2010) Exchange-Traded Funds, Persistence in Tracking Errors and Information Dissemination, Journal of Multinational Financial Management, 20, 214-234.

Tse, Y., \& Martinez, V. (2007) Price Discovery and Informational Efficiency of International iShares Funds, Global Finance Journal, 18, 1-15. access article distributed under the terms and conditions of the Creative Commons by Attribution (CC-BY) license (http://creativecommons.org/licenses/by/4.0/). 